\title{
Discrimination of Artificial and Actual Expression on Face Using sEMG
}

\author{
Ela Naz Döğer ${ }^{1}$, Kadir Gök², Özlenen Özkan ${ }^{3}$, Ömer Özkan ${ }^{4}$, Hilmi Uysal$^{5}$, Övünç Polat ${ }^{6}$, Ömer Halil \\ Çolak $^{7}$ \\ 1, 2, 6,7 Akdeniz University, Faculty of Engineering, Department of Electrical and Electronics Engineering, Antalya, Turkey \\ elanazdoger@gmail.com; gokkadir@gmail.com; ovuncpolat@akdeniz.edu.tr; omercol@akdeniz.edu.tr \\ ${ }^{3,4}$ Akdeniz University, Faculty of Medicine, Department of Plastic and Reconstructive Surgery, Antalya, \\ Turkey \\ omozkan@hotmail.com; ozlenend@yahoo.com \\ ${ }^{5}$ Akdeniz University, Faculty of Medicine, Department of Neurology, Antalya, \\ Turkey \\ uysalh@akdeniz.edu.tr
}

\begin{abstract}
In this study, artificial and actual face expressions have been analysed using RMS and MF features on surface EMG. For this, Surface EMG for 9 young healthy volunteers has been recorded using multichannel. Total face region has been grouped as lower including 3,4,5,7 channels and upper face regions including 9,10,11,12 channels. EMG has been windowed depending on contraction time in expression and obtained partial EMG. Average MF and Average RMS values have been obtained and compared on both of the face regions for happiness and fear expressions. As a result, we found that MF and RMS values have different selectivity characteristic depending on face regions (upper region-lower region) and face expressions (artificial face expressions-actual face expressions).
\end{abstract}

Keywords: Surface EMG, Mean Frequency, Root Mean Square, Facial expressions

\section{Introduction}

Emotional expression is an important part of non-verbal communication used in daily life.[1] Facial expressions (neutral, fear, happy, hate, surprised, angry) are universal.[2] Electromyography (EMG) refers to the collective electric signal from muscles, which is controlled by the nervous system and produced during muscle contraction.[3] Electromyography muscle allows you to record action potentials differences. This method provides to record the differences in the action potentials of the muscle, by applying electrodes on the face muscles. [4].

In this study, Surface EMG recordings have been recorded from 9 young (17-25 years) and healthy volunteers. These volunteers were selected 3 male individuals and 6 females. The expressions of emotions have been recorded with surface electrodes during basic emotions.

In order to evaluate the emotional expressions of these volunteers, they were asked to perform simple facial expressions (artificial happiness, actual happiness and artificial fear, actual fear). Then surface EMG data collected and used to investigate. The results that obtained using RMS and MF features compared.

\section{Recording of sEMG}

Recording was performed in 2 stages by all volunteers. The PowerLab 35/15 recording system was used in the measurements (sample rate $\mathrm{Fs}=2000 \mathrm{~Hz}$ ). During record, high definition videos were captured. EMG signals recorded from individuals with multi bipolar electrodes ( $9 \mathrm{~mm}$ diameter and $20 \mathrm{~mm}$ interelectrode distance), and conductive and adhesive neurodiagnostic gel. Electrodes positions are illustrated (Fig. 1). [5-10] 


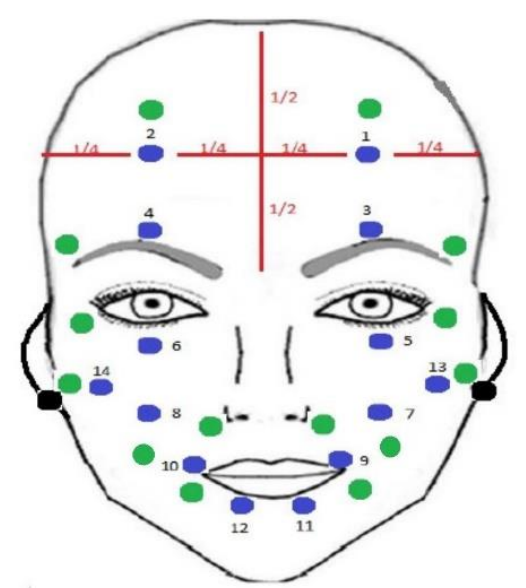

Fig. 1.

In first stage, volunteers were procured artificial face expressions without stimulation. Recording periods consisted of 2 seconds of activation and 3 seconds in a resting position. Facial motions (anger, fear, happiness, hate, surprise and sadness) were performed by all subjects with two sets.

In second stage volunteers were procured actual face expressions with visual stimulation (by watched short movies about related expression).

\section{Method}

Individuals recorded data with surface EMG electrodes, from multi-channel with $2 \mathrm{kHz}$ sampling frequency as bipolar primarily is pre-processed. Initially notch filters (cut-off frequencies, $\mathrm{fc}=50 \mathrm{~Hz}$ and $\mathrm{fc}=350 \mathrm{~Hz}$ ) were applied to the signal in order to remove power line interference. A fourth order Butterworth bandpass filter (10-500 Hz) was used to suppress motion artefacts and noise. Finally, this sEMG signals was analysed with RMS (Root Mean Square) and MF (Mean Frequency) features.

Facial Region Channels grouped by Upper Face (3-4-5-6) channels and Lower Face (9-10-11-12 channels) and these regions also called Orbicularis Oculi Region and Orbicularis Oris Region. Then average of mean frequency (MF) and average of Root Mean Square (RMS) values for each group have been calculated using equations 1-6.

$$
\begin{gathered}
f_{(i) \text { Mean }}=\frac{\int_{0}^{N} f P(f) d f}{\int_{0}^{N} P(f) d f} \\
f_{\text {Channel Mean (upper) }}=\frac{\sum_{i=3}^{6} f_{(i) \text { Mean }}}{4} \\
f_{\text {Channel Mean (lower) }}=\frac{\sum_{i=9}^{12} f_{(i) \text { Mean }}}{4} \\
R M S_{(i)}=\sqrt{\frac{1}{N} \sum_{i=1}^{N} x_{i}^{2}} \\
R M S_{\text {Channels Mean (upper) }}=\frac{\sum_{i=3}^{6} f_{(i) \text { Mean }}}{4} \\
R M S_{\text {Channels Mean (lower) }}=\frac{\sum_{i=9}^{12} R M S_{(i) \text { Mean }}}{4}
\end{gathered}
$$

where $i$ is he number of channel, $f$ is the mean frequency, $p(f)$ is the power spectrum of each channel. 


\section{Results}

MF of artificial happiness expression has approximate equal or higher values with actual happiness expression on upper face region of male and female subjects. Only one subject with actual happy expression has lower MF value. On the contrary, MF values exhibit totally different results on lower face region. In this region, MF of artificial happiness expression has equal or lower values from actual happiness expression. Only one subject with actual happy expression has higher value.
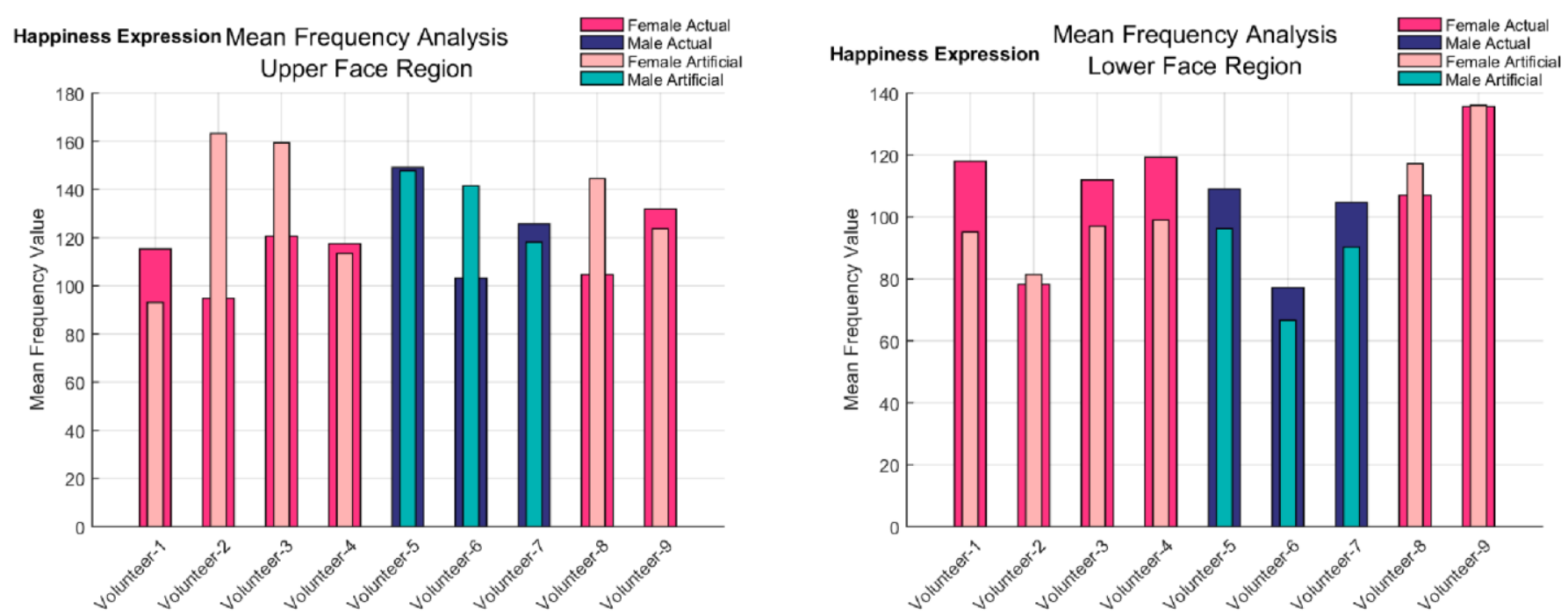

Fig. 2: MF Analysis of Happiness Expression on Upper Face Region. Fig. 3: MF Analysis of Happiness Expression on Lower Face Region.

MF of artificial fear expression has approximate equal or higher values with actual fear expression on upper face region of male and female subjects. On the contrary, MF values exhibit totally different results on lower face region. In this region, MF of artificial fear expression has equal or lower values from actual happiness expression. Only one subject with actual happy expression has higher value.

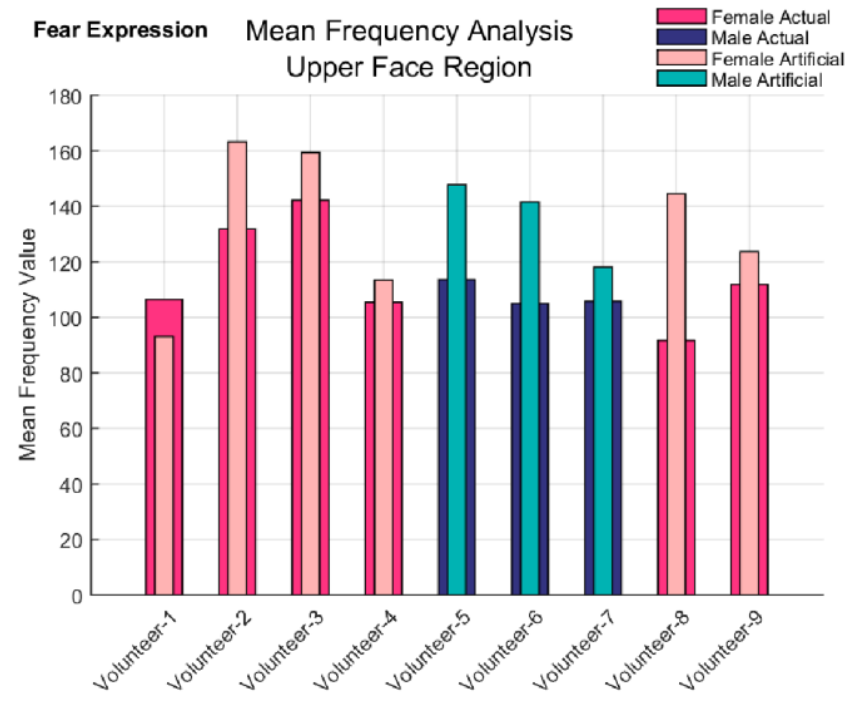

Fig. 4: MF Analysis of Fear Expression on Upper Face Region.

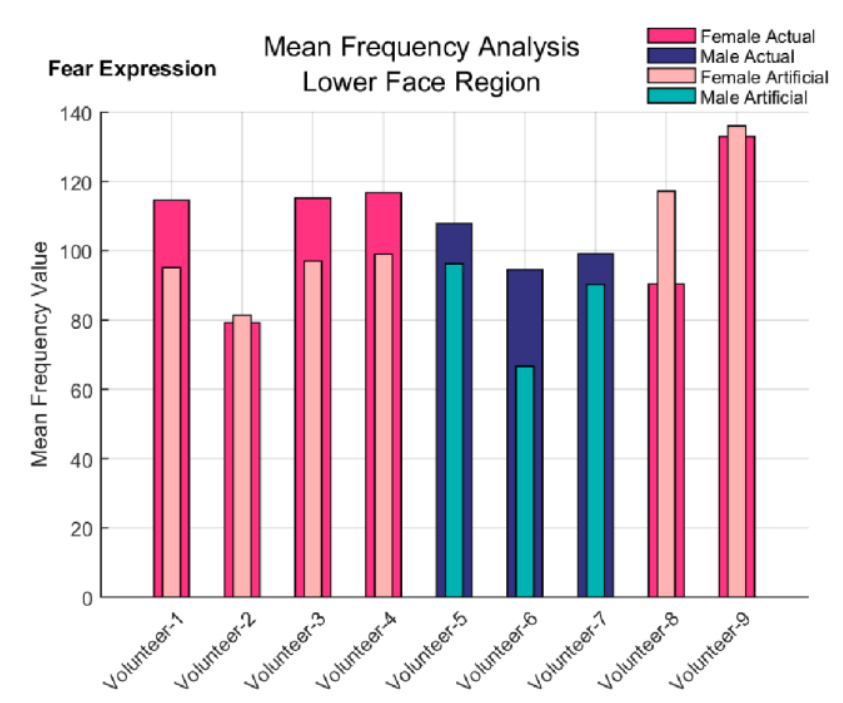

Fig. 5: MF Analysis of Fear Expression on Lower Face Region.

RMS of artificial happiness expression has lower values with actual happiness expression on lower face region of male and female subjects. However upper face region doesn't include a discrimination feature. 

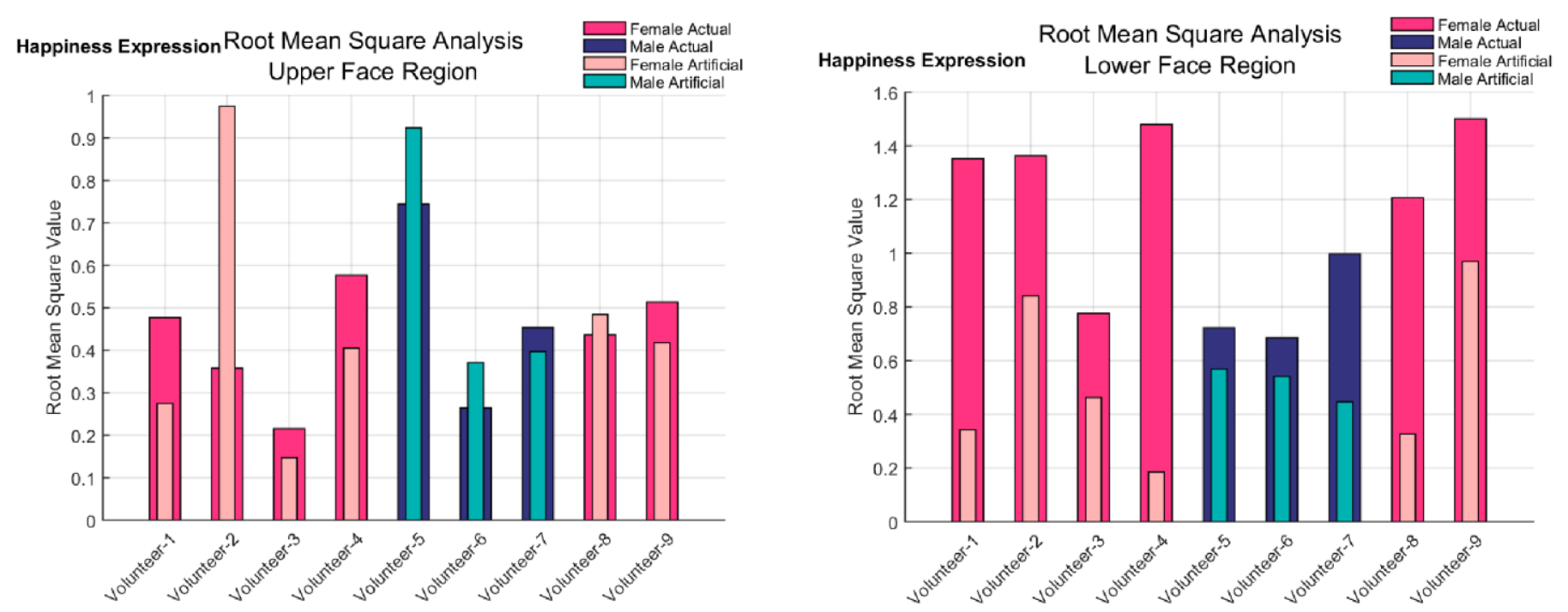

Fig. 6: RMS Analysis of Happiness Expression on Upper Face Region. Fig. 7: RMS Analysis of Happiness Expression on Lower Face Region.

RMS of artificial fear expression has higher values with actual fear expression on upper face region of male and female subjects except one subject. However, lower face region doesn't include a discrimination feature.
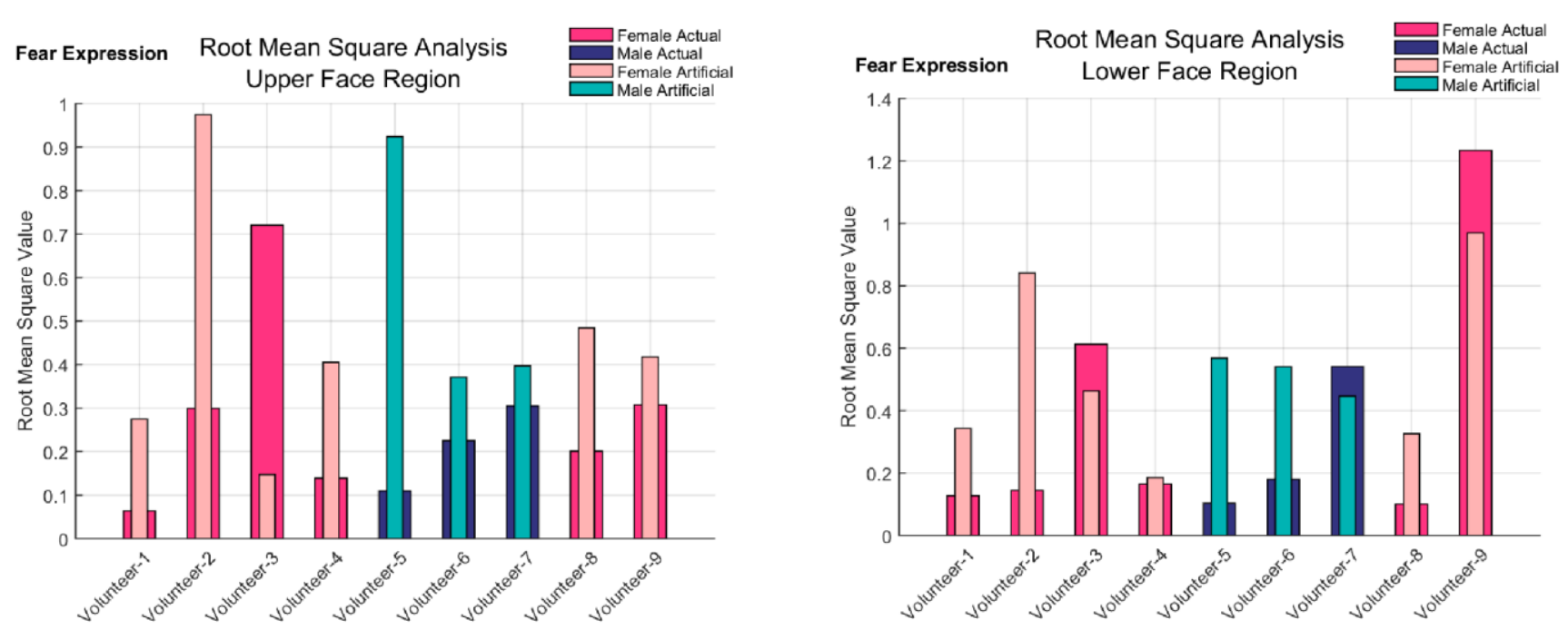

Fig. 8: RMS Analysis of Fear Expression on Upper Face Region. Fig. 9: RMS Analysis of Fear Expression on Lower Face Region.

\section{Conclusion}

MF presents classifiable and decomposable results between artificial and actual happiness expressions both of the upper and lower face regions. This situation is the same with fear expression. RMS values that is most using parameter in EMG has great selectivity on lower face region for discrimination of artificial and actual happiness expressions. In fear expressions, RMS values of upper face regions has powerful selective features but RMS values of lower face region don't reflect a discrimination feature.

This results can be interpreted and used for neurorehabilitation studies and this analyse can be combined with another physiological parameters. 


\section{Acknowledgements}

The research was granted and supported by TUBITAK (Project Number: 1919B011503353). Thanks to all volunteers, and undergraduate students Harun Eralp and Derya Yaman for valuable contributions. Link for our researches, projects, publications http://neuroscience.akdeniz.edu.tr/

\section{References}

[1] M. Batty and M. J. Taylor. "Early processing of the six basic facial emotional expressions," Cognitive Brain Research, vol. 17, no. 3, pp. 613-620, 2003.

[2] P. Ekman and W. V. Friesen. "Constants across cultures in the face and emotion," Journal of personality and social psychology, vol. 17, no. 2, pp. 124, 1971.

[3] D. Farina and F. Negro, "Accessing the neural drive to muscle and translation to neurorehabilitation Technologies," IEEE Rev. Biomed. Eng., vol. 5, pp. 3-14, 2012.

[4] D. S. Tümen and S. G. Arslan. "Çigneme kas aktivitesi ve ölçüm yöntemleri," Dicle Tip dergisi, vol. 34, pp. 316-22, 2007.

[5] H. Uysal, Ç. Topçu, Ö. Özkan, Ö. Özkan, N. E. Barcin, A. Akgül, M. Bedeloglu, E. N. Doger, R. Sever, Ö. Polat, and Ö. H. Çolak, "ID 382-Electrophysiological Evaluation of Emotional Expressions in the Facial Transplantation Patients," Clinical Neurophysiology, vol. 127, no. 3, pp. e127.

[6] Ç. Topçu, A. Akgül, M. Bedeloğlu, E. N. Döğer, R. Sever, Ö. Özkan, Ö. Özkan, H. Uysal, P. Ovunc, and O. H. Colak, "Yüz Hareketlerinin Sınıflandırılması için Yüzey EMG İşaretlerinin Entropi Analizi," in IEEE Sinyal İşleme ve İletişim Uygulamaları Kurultayl, Malatya, Türkiye, 16-19 Mayıs 2015.

[7] H. Uysal, Ç. Topçu, Ö. Özkan, Ö. Özkan, N. E. Barcin, A. Akgül, A. Akgül, M. Bedeloglu, E. N. Doger, R. Sever, O. Polat, and O. H. Colak, "Yüz nakli olgularında duygu ifadelerinin elektrofizyolojik olarak değerlendirilmesi," in 31. Ulusal Klinik Nörofizyoloji EEG-EMG Kongresi, Antalya, Türkiye, 8-12 Nisan 2015.

[8] Ç. Topçu, A. Akgül, M. Bedeloğlu, E. N. Döğer, R. Sever, Ö. Özkan, H. Uysal, P. Ovunc, and O. H. Colak, "Muscle Activity Detection for Basic Movements in Patients with Full Face Transplantation," in 37th Annual International Conference of the IEEE Engineering in Medicine and Biology Society, Milano, İtalya, 25-29 Ağustos 2015.

[9] A. Akgül, M. Bedeloğlu, Ç. Topçu, R. Sever, Ö. Özkan, et al.,"Çok Kanallı Kol Yüzey EMG Kayıtlarında 24 Farklı Hareket Grubu İçin Kanal Etkinliğinin Araştırılması," in 18. Biyomedikal Mühendisliği Ulusal Toplantısı, İstanbul, Türkiye, 16-17 Ekim 2014.

[10] Ç. Topçu, M. Bedeloğlu, A. Akgül, R. Sever, Ö. Özkan, H. Uysal, P. Ovunc, and O. H. Colak, "Yüzey EMG İ̧saretlerinin Higuchi Fraktal Boyutu ile Analizi ve Etkin Elektrot Bölgelerinin Tespiti," in 18. Biyomedikal Mühendisliği Ulusal Toplantısı, İstanbul, Türkiye, 16-17 Ekim 2014. 